\title{
Positron emission tomography cerebral blood flow before and after embolisation of a dural arteriovenous fistulous malformation
}

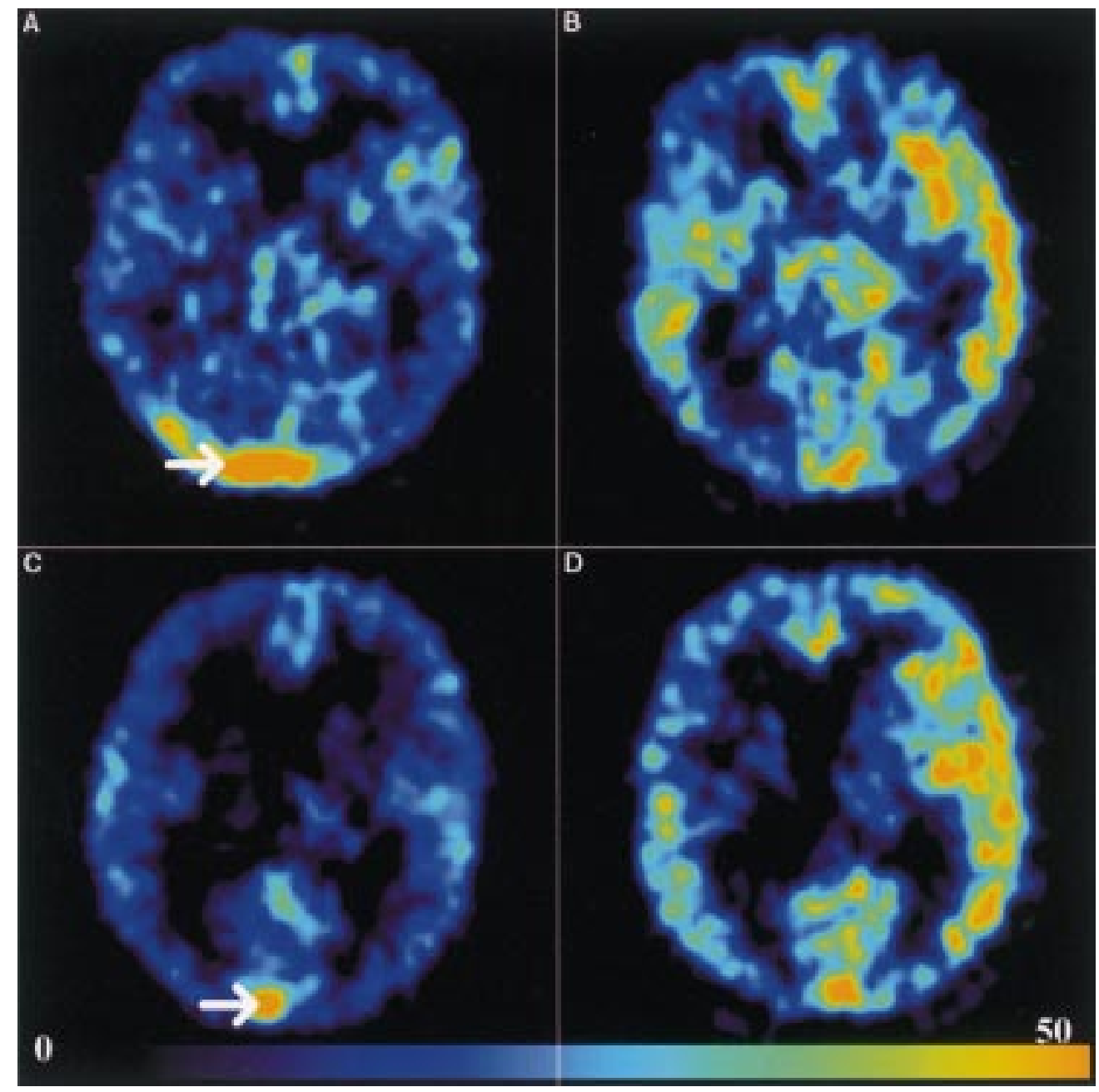

A 26 year old man with Down's syndrome presented with a 9 month history of progressively deteriorating left hemiparesis, seizures, and then persistent coma despite treatment. Magnetic resonance imaging and angiography confirmed the presence of bilateral dural arteriovenous fistulous malformations, the larger being on the right. Positron emission tomography $\mathrm{H}_{2}{ }^{15} \mathrm{O}$ studies (transverse slices A and C) showed high blood flows in the transverse and superior sagittal venous sinuses (indicated by arrows) but globally low cerebral blood flow in both hemispheres (mean of $15.2 \mathrm{ml} / 100 \mathrm{~g} / \mathrm{min}$ ) compatible with the patient's clinical condition. An EEG showed no epileptic activity but did show a right posterior slow wave abnormality attributable to ischaemia, which is recognised with large dural arteriovenous fistulous malformations. ${ }^{12}$

After endovascular glue embolisation of the right arteriovenous fistulous malformation, PET showed improvement in the global cerebral blood flow to a mean of $26 \mathrm{ml} / 100 \mathrm{~g} / \mathrm{min}$ (slices B and $\mathrm{D}$-which are equivalent to slices $\mathrm{A}$ and $\mathrm{C}$ respectively), the EEG abnormality resolved, and the patient went on to recover to his premorbid neurological state.

P S MINHAS

MEMBERS OF THE WOLFSON BRAIN IMAGING CENTRE TEAM Wolfson Brain Imaging Centre, Addenbrookes' Hospital, Cambridge, UK

Correspondence to: Mr P S Minhas, Wolfson Brain Imaging Centre, Academic Department of Neurosurgery, Addenbrooke's Hospital, Hills Road, Cambridge CB2 2QQ, UK. Telephone 00441223331 823; fax 00441223331 826; email psm22@wbic.cam.ac.uk

1 Borden JA, Wu JK, Shucart WA. A proposed classification for spinal and cranial dural arteriovenous fistulous malformations and implications for treatment. F Neurosurg 1995;82:166-79.

2 Vinuela F, Fox AJ, Peltz DM. Unusual clinical manifestations of dural arteriovenous malformations. F Neurosurg 1986;64:554-8. 


\section{Christmas tree sign}

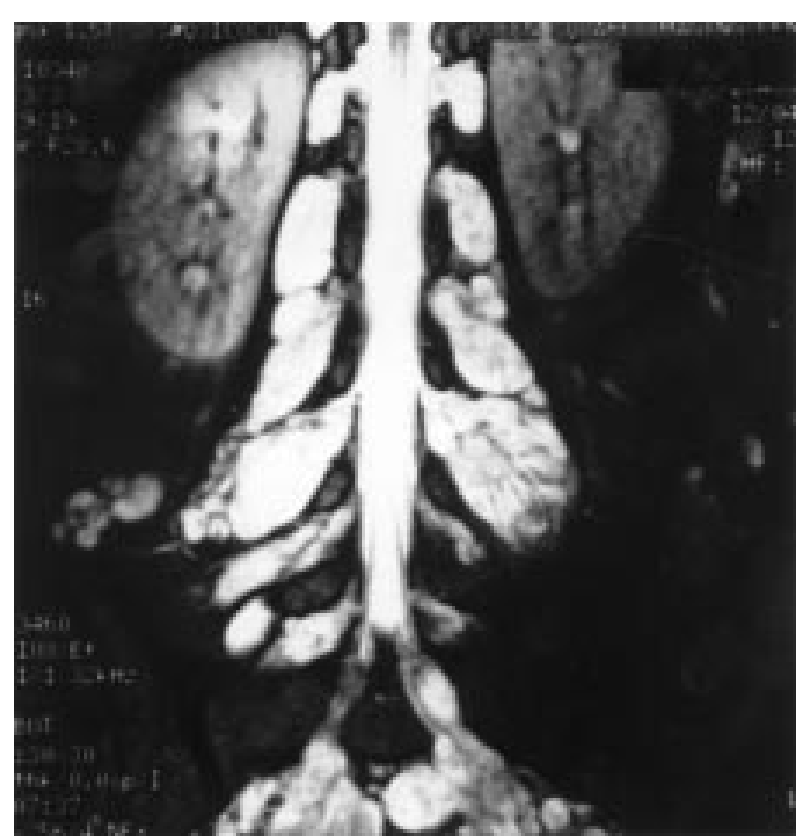

Back pain and sciatica in patients with neurofibromatosis may result from a multitude of pathological processes which include scoliosis, degenerative diseases of the spine, and spinal tumours. Neurofibroma, schwannoma, meningioma, and glioma can all occur. When specific tumours are responsible for the symptoms, surgical excision can offer effective treatment. Many patients, however, have widespread disease. We recently treated a patient with multiple neurofibromas which involved several nerve roots and the cauda equine (figure). The extensive distribution of the tumours produced an MRI picture resembling a Christmas tree. In patients with "the Christmas tree sign" the challenge is in the correct diagnosis of those tumours which produce the symptoms if surgery is to remain a realistic management option.

$$
\begin{array}{r}
\text { KEYOUMARS ASHKAN } \\
\text { ADRIAN TH CASEY } \\
\text { Department of Neurosciences, } \\
\text { Charing Cross Hospital, } \\
\text { London, England }
\end{array}
$$

Correspondence to: Mr A Th Casey, National Hospital for Neurology and Neurosurgery, Queen's Square, London WC1N 3BG, UK.

Telephone 00441718373611.

MRI demonstrating the Christmas tree sign. 